\title{
Sustentabilidades das ONG
}

\author{
Marina Félix de Melo \\ Doutora em Sociologia pela Universidade Federal de Pernambuco \\ Professora da Universidade Federal de Alagoas \\ melomarina@msn.com
}

\begin{abstract}
Resumo O presente artigo discute as sustentabilidades das Organizações Não Governamentais (ONG) como eixo analítico no conhecimento dos processos de profissionalização do Terceiro Setor. Percebemos a sustentabilidade financeira como um instrumento que possibilita e, ao mesmo tempo, limita a existência das organizações. A investigação apoia-se no paradigma qualitativo de análise e encontra, como resultado, um Terceiro Setor frágil consoante à sustentabilidade, em que a profissionalização institucional das ONG tem papel importante nesse cenário. Ainda que profissionalização e sustentabilidade sejam dimensões analíticas positivamente correlacionadas, a profissionalização de uma organização não assegura a instituição quanto a sua sustentabilidade financeira e suas necessidades materiais que possibilitam o funcionamento da ONG.
\end{abstract}

Palavras-chave: sustentabilidades, financiamento, profissionalização, ONG.

\section{Sustentabilidade financeira como solução e entrave}

O Terceiro Setor entrou no cenário mundial a partir de realidades concretas que possibilitaram sua emergência e permanência na sociedade. Disso, estamos a falar em sustentabilidades, no plural, ao passo que a sustentabilidade das ONG, embora seja tema altamente relacionado à manutenção financeira das instituições, é um ponto ainda mais complexo, pois não só de dinheiro e recursos financeiros vive uma organização. Logo, surgem-nos duas questões essenciais: o que são sustentabilidades de ONG?; e por que estudar as sustentabilidades dessas entidades com relação à profissionalização ${ }^{1}$ do Terceiro Setor?

A palavra sustentabilidade tem origem latina (de sustentare, que significa sustentar) e está ligada aos termos: apoiar, defender, cuidar, favorecer, conservar. É aqui entendida como tudo aquilo que faz que uma instituição seja possível, desde a mola propulsora dos indivíduos que a fundam até as concepções ideológicas dos indivíduos envolvidos, as raízes éticas que seguem, as missões que perseguem, o capital humano do qual dispõem ${ }^{2}$ e, sobretudo, as possibilidades materiais que permitem o exercício dessas funções. É bastante comum que essa

1. As principais dimensões analíticas consideradas neste texto para caracterizarmos a profissionalização institucional das ONG são: percurso escolar e grau de escolaridade dos agentes que na organização trabalham; nível de especialização nas atividades desenvolvidas; forma como ocorre a divisão de tarefas administrativas; interação entre as relações primárias e secundárias de sociabilidade no trabalho; capacidade de articulação das entidades em redes de cooperação; estratégias e planejamento institucionais e dinâmica de avaliação do trabalho interno. Essas dimensões são especificadas, não sendo excludentes, tampouco exaustivas.

2. Salamon denota que há uma crise de sustentabilidade de capital humano no Terceiro Setor na medida em que a ideia de democracia ganha fôlego mundo afora e agentes de ONG assumem cargos de governo em substituição a antigos funcionários, deixando as organizações com déficit de recursos humanos. "É nesse sentido que o terceiro setor se 
sustentabilidade, de um plano mais geral, seja confundida com a sustentabilidade financeira apenas. Faz sentido esse conflito ao passo que a sustentabilidade financeira hoje se apresenta como um dos principais elementos decisivos das instituições, para não dizermos: entrave. Entretanto, a sustentabilidade financeira se coloca como um processo de "caça", ao mesmo tempo em que passa por ponderações múltiplas e envolve não apenas o que está prescrito nos estatutos das organizações, mas sim, as possibilidades de manobra das ONG diante dos imponderáveis da vida real consoante às oportunidades (ou à sua falta) de editais de financiamentos ou demais maneiras de angariarem verbas para que desempenhem suas funções sociais. $\mathrm{O}$ mais curioso disso, e o que calha como uma tentativa de resposta à segunda questão, é que esses elementos (dinheiro e ética, grosso modo) não encenam cotidianamente como categorias estanques. As entidades tendem a questionar (ou não, e aí já tomamos esse "não" como uma dimensão analítica) as maneiras de receberem dinheiro, como chegarem até as verbas e o que é aceitável dentro de padrões éticos pré-estabelecidos. Esse tipo de tensão institucional ocorre quando, por exemplo, Organizações Não Governamentais de apoio à saúde se recusam a receber patrocínios de empresas de fumo.

Logicamente, as ONG precisam de recursos financeiros para se manterem e a forma como conseguem isso, a capacidade de articulação, se coloca como um elemento, uma dimensão analítica importante para pensarmos nos graus de profissionalização dessas organizações. A lógica mais linear aqui seria: uma ONG que tenha um grau de profissionalização institucional elevado tende a possuir mecanismos mais articulados para captar informações e angariar fundos para sua existência, pois essa capacidade diz respeito a treinamento de pessoal, especialização, experiência com a lógica do Terceiro Setor etc. Essa inquietação de sustentabilidade está altamente imbricada à noção de autonomia das ONG (limites da flexibilidade dessas entidades diante de uma sociedade regida também por Mercado e Estado), entretanto, por hora nos manteremos à lógica do como é possível a existência de ONG.

Como dissemos, a sustentabilidade não diz respeito apenas à sustentabilidade financeira, todavia, para os nossos presentes propósitos, vamos dar uma atenção especial a essa última. Vamos nos "contradizer" em alguma medida e utilizar daqui em diante o termo "sustentabilidade" de forma reduzida, para nos referirmos à sustentabilidade financeira e, quando não, faremos a menção exata sobre o que versamos.
Nessa vereda, uma das principais perturbações que encontramos ao investigarmos a sustentabilidade dessas entidades está sobre que tipo de instituição tratamos já que o Terceiro Setor é formado por uma pluralidade de organizações que vão desde cantinas de distribuição de sopas a instituições culturais de focos e administrações amplos e complexos. Mesmo diante dessa pluralidade, autores como Salamon (1997) enxergam que o Setor, de maneira geral, localiza-se em um ecossistema frágil, suscetível a ameaças externas na medida em que tem como incertas suas fontes de financiamento, por mais firmadas e legitimadas que sejam a um determinado espaço de tempo. Um edital provindo de uma instituição pública é capaz de sustentar um projeto de uma ONG até a data estabelecida em acordo, entretanto, muitos desses financiamentos não são perenes, deixando as entidades em uma base pendular significativa entre o ter e o não ter recursos sob determinado tempo. Isso, é claro, muito lembra a lógica de mercado e este possui margens de manobra específicas à sua essência para tratar com as sazonalidades de suas áreas ao lidar, por exemplo, com a concorrência, medidas que, ao Terceiro Setor, ainda se colocam como realidades impactantes, especificamente, porque o Setor não trabalha sob a mesma dialética de mercado e, ainda que muitas entidades sejam assimiladas a tal, possuem fins distintos.

Antes de versarmos sobre os problemas mais peculiares da sustentabilidade, convém balizarmos alguns dados sobre o Terceiro Setor que mostram o quão substancial tem sido sua força econômica ainda que, por vezes, ele permaneça invisível como realidade (Salamon, 1997, p. 93). Salamon realizou uma pesquisa no começo da década de 1990 com sete países (Estados Unidos, Reino Unido, França, Alemanha, Itália, Hungria e Japão) no qual constatou que o Terceiro Setor empregava neste conjunto cerca de 12 milhões de pessoas com pagamentos relativos a trabalho de tempo integral, além de 5 milhões de voluntários. Isto é, há mais de vinte anos o setor já empregava naqueles países cerca de $10 \%$ dos ativos. O mais interessante achado da pesquisa foi que as doações caritativas - personalizadas e que partem geralmente de indivíduos isolados - eram as de menor impacto, cerca de 10\% dos auxílios, perdendo de forma significativa para os recursos provindos do Estado e do Mercado. Na Alemanha e na França, por exemplo, o Estado chegava a sustentar $60 \%$ das organizações na altura. No Brasil, dados do Instituto Brasileiro de Geografia e Estatística (IBGE) colhidos em 2005 apontam que o País possuía 338 mil fundações privadas e associações sem fins lucrativos, empregando, na época, 1,7

torna vítima de seus próprios êxitos. Ironicamente, se o terceiro setor pode contribuir para a democracia, a curto prazo a democracia pode sugar a força do terceiro setor" (Salamon, 1997, p. 106). Com base nisso, o autor argumenta sobre a importância de o Terceiro Setor reforçar suas relações com o Estado e com o Mercado. 
milhão de pessoas, o que representa 5,3\% dos empregos brasileiros. (IBGE, 2008, p. 58). (excetua-se aí o voluntariado e as possíveis prestações de serviços não declaradas).

Sob tal conjuntura, a sustentabilidade se coloca como um desafio. Quais são as margens de manobra das ONG diante desse contexto concreto? Muitas instituições nasceram por meio de esforços pessoais, doações estrangeiras, públicas ou privadas. À medida que ganham espaço, os problemas aos quais se colocam ganham formas e tamanhos ainda mais complexos e pedem, por sua vez, outras bases de suporte financeiro. Passa a haver uma disputa interna dentro das ONG para o levantamento de verbas, a gerar uma crise no Terceiro Setor e, aí, a relação do Terceiro Setor com agências de cooperação internacionais (as ONG construídas para angariar fundos a outras $\mathrm{ONG}$ ), Estado e Mercado tensiona, gerando para Salamon dois tipos de desafios de colaboração (Salamon, 1997, p. 107). O primeiro, a colaboração com o Estado que, desde o início da década de 1990, tomou papel determinante na sustentabilidade do Terceiro Setor, nomeadamente nos países da Europa ocidental e nos Estados Unidos. Já na América Latina, África e Ásia sua participação foi mais tímida ao passo que o histórico dessas organizações tinha bandeiras antiestado (o ranço do termo "não governamental"), o que caracterizou dificuldades de colaboração entre os setores. O segundo desafio, a colaboração com o Mercado, no qual o Terceiro Setor objetivaria convencer os empresários do papel que desempenha, de que está capacitado ao atendimento das necessidades públicas.

Nessa segunda colaboração, com o Mercado, é que reside um dos pontos mais tensos sobre a sustentabilidade do Terceiro Setor atualmente, quiçá, mais do que com sua relação com o Estado que, grosso modo, já se tornou um quadro no qual as $O N G$ não são antiestado, ainda que estejam em voga as discussões clássicas de se entender se o Terceiro Setor está a realizar atividades que deveriam ser desempenhadas pelo Estado. Aparte essa questão do Estado, a relação com o Mercado ganha dois caminhos espinhosos porque está em jogo não apenas se, e como, receber recursos do Segundo Setor. Existe também a atual caracterização de mercado que invade o Terceiro Setor, fruto, sobretudo, do processo de profissionalização das instituições. Ana Claudia Teixeira (2003, p. 100) relembra que as ONG não estão imunes à lógica empresarial e que muitas possuem um formato mais próximo de uma empresa de consultoria e prestação de serviços do que propriamente de instituição destinada ao fomento de cidadania. Ao fim e ao cabo, há de se considerar que o que essas entidades oferecem à sociedade são produtos e serviços, ainda que produtos diferentes e qualificados, ou mesmo que tenham motivações distintas do Segundo Setor.

Relembramos o que diz Salamon (1997) sobre a força econômica que o Terceiro Setor gira hoje em dia, essencialmente, no tocante às ocupações que cria na sociedade. Tudo isso, no entanto, não significa que entidades sejam instituídas meramente com o intuito de prestação de serviços a la Mercado, o que também não significa que não sejam, isto é, seria prematuro afirmarmos a priori como a relação que elas mantêm com o Mercado influencia em suas criações e no suposto desenvolvimento de um ethos, digamos, empresarial de ONG. Contudo, não podemos negar que em alguns ambientes de ONG existe a noção de "clientela", de que a entidade disponibiliza "produtos" a "clientes", bem como a aplicabilidade de termos empresariais, a exemplo de "público-alvo".

Embora o foco de atenção maior aí seja a venda de produtos, salientamos que as ONG, todavia, não vendem qualquer tipo de produto, pois, mesmo quando se veem nessa posição, se colocam como facilitadoras de um produto especial, diferenciado, formativo, de caráter educacional e, especializado. Mediante semelhanças a um perfil empresarial, essas ONG não podem restringir o universo de atuação a "clientes" que podem ou não pagar, haja vista as predisposições primeiras dessas instituições, que prestam serviços públicos e gratuitos, salvaguardadas raras exceções contextualizadas.

Até aqui, versamos sobre o Terceiro Setor em relação com o Primeiro e o Segundo, mas existe a relação do Terceiro Setor consigo, relação essa que transpassa a ideia de redes de ONG para troca de informações de suas aéreas de atuação ou trocas de projetos. Não que essa última perspectiva de redes não seja importante às $\mathrm{ONG}$, muito pelo contrário, é um dos grandes indicadores de profissionalização institucional e suporte de diversas ordens dessas organizações atualmente. Todavia, agora versamos sobre as agências de cooperação internacional. No começo da década de 1990, quase 76\% das entidades ligadas à Associação Brasileira de ONG (Abong) no Brasil eram sustentadas, em alguma medida, por agências de cooperação que são, grosso modo, ONG estrangeiras que financiam e distribuem recursos a ONG. Vale salientar que isso não indica que essas $76 \%$ fossem sustentadas apenas por agências de cooperação, mas por elas também, porém igualmente por fontes diversas de recursos, sobretudo, como vimos, Estado e Mercado. Tais agências apresentam diferenças estruturais de acordo com seus países de origem e, em verdade, funcionam como empresas administrativas na medida em que possuem especialização de gestão para coordenar, entre as ONG concorrentes dos recursos, as verbas que lhes são passadas pelos demais 
setores. Logo, temos uma espécie de terceirização do Terceiro Setor.

Nas últimas duas décadas, a maneira de atuação dessas agências de cooperação internacionais face aos investimentos no Brasil modificou-se, de acordo com Lebon (1998), por três razões especiais: após a queda do muro de Berlim as agências se voltaram mais aos problemas do Leste europeu e da África; o Plano Real tornou a moeda brasileira mais valorizada, havendo momentos em que seu câmbio equiparou-se com o dólar, disso, tornava-se mais caro sustentar projetos no País e; mudanças sobre gestão de trabalho elevaram ainda mais a valorização de melhor aproveitamento de tempo no horário de serviço, o que pedia das organizações brasileiras planos mais bem geridos e articulados nesse sentido. A relação do Terceiro Setor com as agências de cooperação pode ser entendida como uma ligação essencial do fator sustentabilidade das ONG e profissionalização dessas, porque aí encontramos o motor de funcionamento do sistema que interconecta os setores. Outro aspecto mais contemporâneo acerca da redução de presença das agências de cooperação internacional no Brasil é que as políticas sociais dos governos Lula e Dilma partiram do pré-suposto de erradicação da miséria, principal foco de atuação dessas agências. Logo, como dito, ainda que as políticas desses governos não tenham superado em todos os sentidos a miséria e a pobreza, muito dessa imagem se "vendeu" e as agências passaram então a se dedicar a países que não tinham tal apoio político ou planos sociais estatais desenhados como os brasileiros (Abong, 2010, p. 2627). Salientamos ainda que as mudanças de foco da cooperação internacional são guiadas, especialmente, pelos países do Norte e suas iniciativas da sociedade civil, e ainda que as verbas dispensadas pelas agências são provenientes não apenas de doações, mas também dos governos, passíveis a crises e remodelações políticas a menudo. (Abong, 2010, p. 29).

O Terceiro Setor cria estratégias financeiras de subsistência cada vez mais específicas e especializadas à sua localização no triângulo não equilátero de setores. Crescem, em paralelo aos estudos acadêmicos sobre as instituiçõos, as publicações de manuais sobre como criar e sustentar uma ONG, quais os mecanismos administrativos que se aproximam do setor de Mercado e que devem ser tomados como princípios de impulso às entidades. Essa produção, reflexo do que chamamos de boom da profissionalização a partir da década de 1990 , é balizada nos aspectos mais gerais da especialização, afinal, tira-se daí o fluxo de profissionais de diversas áreas do conhecimento que passam a se especializar em questões pertinentes ao Terceiro Setor, a complexar seus quadros de gestão e funcionamento.

$\mathrm{Na}$ literatura pertinente à questão do planejamento nas ONG, a ideia mais em voga é aquela de vinculá-lo à necessidade de formação especializada e profissional, sem esquecer que o momento técnico faz parte dos próprios objetivos políticos existentes dentro da organização (talvez resultantes de disputas internas para seu estabelecimento). Segundo Corcione (1998), o planejamento não pode ser elaborado como um mero calendário de atividades, pois daí resultaria uma série de eventos sem interligação, soltos e desprovidos de objetivo central capaz de coordená-los. O autor acredita que o momento do planejamento não pode ser exclusivo de um grupo perito, com formação profissional especializada (composto apenas por diretores e presidentes das instituições, por exemplo). Tal fato isolaria a participação dos demais membros da organização, inviabilizando o engajamento coletivo e, consequentemente, político na fase de elaboração do plano de atividades - o que se refletiria na execução das tarefas da ONG. Logo, poderíamos afirmar que o aspecto técnico é mais um momento das definições políticas no interior de uma ONG; e sua forma de planejar e executar as tarefas será considerada mais ou menos autoritária e democrática segundo o formato em que as decisões mais importantes foram tomadas, por um grupo restrito ou com ampla participação de seus membros. Por investigações concretas, resultantes da tese de doutoramento sobre profissionalização nas ONG (Melo, 2013), conseguimos perceber em que medida o boom de profissionalização no Terceiro Setor influencia no funcionamento das organizações, nas percepções éticas de seus agentes atuantes, na construção de como esses agentes entendem o trabalho das ONG mediante um contexto maior que inclui o Estado, o Mercado e as agências de cooperação.

Para investigarmos tais fenômenos nas ONG é igualmente necessário considerar a dinâmica do processo de especialização nas sociedades modernas. Quanto à dinâmica própria das atividades especializadas, Bauman (1999), coloca a especialização como uma busca frequente e incessante, tornando-se cada vez mais comum, mas isso se daria porque ela se autorreproduz. Em outras palavras, o conhecimento especializado não teria uma valorização una, em si mesmo, não se autossatisfaria, gerando sempre mais a busca pelo novo e pelo desenvolvimento das atividades prestadas. Todavia, nessa linha de argumentação plantada pelo autor, a especialização, ao mesmo tempo em que é criada para solucionar problemas, finda por gerar mais problemas que só podem ser solucionados com mais conhecimento especializado, ou seja, gera-se um círculo vicioso.

No tocante ao aspecto ético presente no processo de especialização, há obras clássicas do pensamento social que se referem à especialização como elemento ligado à divisão do trabalho social. Adam Smith, em A riqueza das nações (1776), foi o primeiro a tentar teorizar essa divisão e foi também o criador do ter- 
mo, já percebendo como a especialização econômica pressupunha um elemento de ordem moral. Foi, porém, com Émile Durkheim, em sua obra Da divisão do trabalho social (1893), que o processo de especialização passou a ser visto como um fato objetivo que deve ser estudado em si mesmo e que o pesquisador deve investigar para que ela serve e de que depende (Durkheim, 1999 [1893]). Destarte, o autor advoga que não é apenas nas fábricas, ou seja, no terreno econômico, que esse fenômeno ocorre, estando presente em outros níveis da vida social, desempenhando funções políticas, administrativas, artísticas, científicas etc. Em suma, a especialização (e a divisão do trabalho) seria um fenômeno ético e moral atuante de maneira geral em toda a sociedade. ${ }^{3}$ Esses elementos se enlaçam à problemática da sustentabilidade porque a moral é um elemento negociável e elástico, sujeito a percepções variadas e, em ligação a esta, a ética é uma construção não apenas particular a cada ONG e à noção de Terceiro Setor mais ampla, mas também é a força motriz de uma instituição, atuante como elemento ímpar nas resoluções práticas da entidade. ${ }^{4}$

Consoante ao problema da sustentabilidade financeira das ONG como um "estimulador" da tensão de como gerir a profissionalização nessas entidades, Leilah Landim, em entrevista cedida à Revista do Terceiro Setor (Landim, 2002b), ao ser indagada se o financiamento do governo e de empresas às ONG interfere ou não na independência das organizações, declara que o fato dessas serem dependentes dos demais setores interfere sim em suas agendas. Landim aponta o erro de muitas instituições que, em busca da chamada autossustentabilidade financeira, se voltam ao mercado e passam a vender objetos, por exemplo, pois podem findar por se desvirtuarem de seus objetivos, afinal, o objetivo das ONG não é mercadológico. Landim afirma que o problema da sustentabilidade financeira sempre se fará presente de acordo com o contexto no qual essas organizações estão inseridas. A tal cenário, surge o que denotamos anteriormente sobre a eclosão de uma literatura específica ao Terceiro Setor e verdadeiros manuais de sobrevivência em meio a tal contexto de busca de sustentabilidade financeira. Não apenas manuais, mas também parte da produção acadêmica que reflete o Terceiro Setor passa em mãos dos agentes dessas organizações e prima não apenas por uma sistematização do como fazer uma ONG, mas principalmente, levanta os problemas mais ordinários a tais instituições referentes às suas sustentabilidades. Falemos de alguns desses problemas e de estratégias esboçadas nessa literatura mais geral.

\section{A corrida pela receita de "ingredientes técnicos" e a diversidade das fontes}

Takeshy Tachizawa possui obra dedicada a um tipo de literatura mais específica às ONG e distribui as estratégias financeiras das entidades nos níveis estratégico e operacional. O primeiro diz respeito à obtenção de recursos financeiros e o segundo, à gestão dos fluxos de caixa das instituições. As decisões estratégicas, ligadas à captação de recursos nos demais setores, ocorrem concomitantemente às decisões operacionais, sendo estas da ordem de gestão de fluxo de caixa de monitoramento e avaliação de projetos (Tachizawa, 2002, p. 175). O Terceiro Setor, em busca da sustentabilidade financeira, tende a elaborar uma cadeia produtiva que liga os fornecedores aos beneficiários de modo a passar por processos produtivos e de apoio.

As principais fontes de obtenção de recursos financeiros para as ONG são: agências internacionais de cooperação não governamentais; vendas de produtos/serviços; agências de cooperação multilaterais; agências de cooperação bilaterais; órgãos nacionais de governo; doações individuais; empresas; fundações nacionais; outras (Tachizawa, 2002, p. 176). Todavia, salientamos que esta lista arquitetada por Tachizawa não indica uma ordem de principais fontes de financiamento, tampouco é um guia hierárquico de "por onde começar" a angariar fundos a uma ONG, haja vista as peculiaridades locais de onde estão inseridas, bem como o tipo de missão que carregam, como focam seus objetivos etc. Vemos que são, grosso modo, as principais indicações às ONG. A essas indicações, soma-se uma expressividade cada dia mais em voga em ambientes comuns ao Terceiro Setor, a exemplo do cuidado em que os agentes atuantes de ONG devem ter ao se depararem com um cenário de competitividade, devendo esses aprimorar e inovar pedidos de financiamento. Há a preocupação sobre como as ONG devem se mostrar a um suposto financiador, ou sobre o material que eventualmente devem portar em um contato dessa relevância.

A Abong é uma das instituições que atualmente tem produzido parte significativa da bibliografia

3. A moral, que é um cimento social, é tratada por Durkheim como um sistema de regras de conduta. Todavia, distinguindo as regras morais de outras regras, Durkheim observa que as regras morais possuem uma autoridade especial, ou seja, a obrigação é uma das primeiras características da regra moral (Durkheim, 1970 [1906]). Durkheim entendia que os fatos morais eram fenômenos como outros, isto é, que a moral era um sistema de fatos realizados, ligados ao sistema total do mundo (Durkheim, 1995 [1983]).

4. Aqui referenciamos os contributos de Weber relativamente à questão da burocracia que sustenta teorias administrativas e de gestão pertinentes à sociologia das organizações e, também, a contribuição de Marx acerca da divisão do trabalho que, embora não façam parte do escopo analítico do presente artigo, dizem respeito aos pressupostos teóricos e dimensões nele tratados. 
sobre as ONG, bem como uma literatura específica ao público de agentes atuantes. A posição da Abong nesse processo de empoderamento do Terceiro Setor não é apenas de dar captação, tampouco possui um posicionamento apenas crítico desse tipo de produção literária mais prática sobre o tema da sustentabilidade. Por reunir um elevado número de entidades em uma complexa rede de relações, a instituição se coloca como uma facilitadora voltada ao desenho de estratégias múltiplas de captação de recursos. Em ONGs: repensando sua prática de gestão (Abong, 2007), os organizadores do livro, publicado pela Abong, esboçam um quadro lógico de localização das ONG em uma rede de relações que considera, com base na missão, elementos como o desenvolvimento institucional interno e a formação que chegam às $O N G$, aos órgãos públicos, aos movimentos sociais e à própria Abong por meio da visibilidade.

Criou-se um "mercado" de cursos e estruturas de consultorias para sustentabilidade de ONG. Oficinas oferecidas pela Abong no Brasil e detalhadas em seus livros diagnosticam necessidades e potencialidades das organizações para que essas diversifiquem a captação de recursos, para que saibam como sensibilizar os possíveis financiadores etc. Ao correr dessa prestação de serviços de ordem administrativa, entram em cena preocupações éticas sobre como ponderar uma organização com base em parâmetros de enfoques sistêmicos e gerenciais, a passar por quadros estratégicos/metodológicos clássicos, como por exemplo, o Zopp (Planejamento e Projetos Orientados por Objetivos), o PES (Planejamento Estratégico Situacional), o Mapp (Método Altadir de Planificação Popular) e o PIM (Monitoramento Participativo do Impacto). A isso, somam-se os cuidados sobre a avaliação da aplicação dessas metodologias administrativas às $\mathrm{ONG}$ por parte da mesma literatura específica voltada aos agentes atuantes das entidades.

As noções de captação de recursos e sustentabilidade são envolvidas pelas principais preocupações: projetos e relatórios bem-estruturados; sistemática de monitoramento da captação; contabilidade transparente e organizada; estrutura de custos racionalizada; apresentação pública de suas fontes de receita, relatórios técnicos e financeiros (Abong, 2007). Acrescentemos aí os debates sobre a ética nessa capacitação, ou seja, até que ponto as ONG podem e/ou devem "apelar" por recursos, considerando que muitas dessas organizações possuem um estoque de imagens que pode ser figurado, quando de mau uso, como propagandas apelativas aos financiadores.

O material produzido e destinado a administrações específicas de ONG muito segue às atuais cartilhas administrativas e, embora encontremos em cada ramo de administração suas peculiaridades (administrar uma empresa privada e uma ONG são ta- refas distintas), existem pontos em comum baseados nas lógicas de relacionamentos institucionais, gerência interna etc. Tais métodos também se colocam a mudanças e, como pontua Salamon, um dos desafios do Terceiro Setor não é criar estruturas sociais inteiramente novas, mas sim, aplicar novas formas de associação às estruturas tradicionais da vida comunitária (Salamon, 1997, p. 101). A literatura de cunho "métodos e técnicas", do como operar uma instituição, não é a única fomentada por instituições como a Abong que, por exemplo, publica relatórios nacionais e internacionais de intervenções sociais, bem como parte significativa de teses e trabalhos reflexíveis realizados, sobretudo, no interior das entidades.

Consoante aos mecanismos de busca por viabilização de sustentabilidade, nomeadamente ao caso brasileiro, estão as noções de "Responsabilidade Social Empresarial" (RES) e "Investimento Social Privado" (ISP). A primeira é lema do Instituto Ethos e a segunda, do Gife, ambas são organizações empresariais sem fins lucrativos fundadas na década de 1990, quando do boom da profissionalização do Terceiro Setor no Brasil. O Ethos reúne 112 empresas filiadas e o Gife 1.396. Ambas têm o discurso de que o Estado não pode dar conta dos problemas sociais sozinho e de que as empresas privadas precisam fazer parte do trabalho não cumprido pelo Estado, no que reúnem um potencial empresarial com números que parecem "assustadores" a uma primeira instância. O Gife aglomera empresas que hoje são responsáveis por $35 \%$ do PIB brasileiro, a maioria são pequenas e médias empresas localizadas no Sudeste do País (75\% e, consideremos que $53 \%$ apenas no estado de São Paulo). O Ethos, que embora agrupe uma quantidade mais tímida de empresas, detém "a nata do empresariado brasileiro", como denota Leite $(2010$, p. 86$)$ ao observar que o Ethos é montado por empresas como o Bradesco (e a fundação Bradesco) e a Rede Globo de Televisão (e sua Fundação Roberto Marinho). Entrementes, apesar de o Gife, por exemplo, enxertar no setor social de arte e desenvolvimento cerca de 1,15 bilhões BRL ao ano, só o rendimento de uma empresa como o Bradesco chega a 10 bilhões BRL nesse mesmo período, grosso modo.

Disso, passamos a pensar o que estimula o empresariado e, mesmo em função ou não de seus estímulos a investimentos no Terceiro Setor, qual o impacto que este tem dentro da sustentabilidade das ONG. Até que ponto, ainda que sob os lemas de RES ou ISP, o Mercado participa dessa economia? Ainda que muitas empresas invistam nas ONG, por marketing ou por obterem algumas isenções de impostos, como elas se localizam diante do cenário maior de possibilidades de financiamento ao Terceiro Setor, sobretudo, quando imaginadas junto ao Estado e às agências internacionais? 
Em pesquisa governada por Taciana Gouveia (Gouveia; Daniliauskas, 2010), encontramos um leque de dados que dizem respeito à aplicação dessa busca de sustentabilidade por parte das instituições integradas à Associação Brasileira de ONG. ${ }^{5}$

Calha salientarmos que embora tal pesquisa seja restrita ao universo da Abong, ela é de uma singularidade importante ao nosso foco, pois demonstra como tem se dado a captação de recursos dessas ONG associadas, nomeadamente, no que diz respeito a quem oferta sustentabilidade financeira às entidades: se mercado, Estado, cooperações internacionais, e assim por diante. Sob outra perspectiva, a pesquisa das Fundações e Associações Sem Fins-Lucrativos (Fasfil), realizada pelo IBGE (2008), compreende o universo do que entendemos como ONG no Brasil, todavia, não chega a ter como proposta uma revisão mais precisa das fontes de financiamento dessas, haja vista a amplitude do universo pesquisado pelo IBGE. De outra mão, a pesquisa da Abong sobre sustentabilidade possui um universo de menos de 270 entidades que são peculiares, pois fazem parte de um modelo típico-ideal de ONG brasileira, haja vista os parâmetros e as representações que perpassam o ser ou não ser uma organização associada à Abong. Falamos aqui, grosso modo, de instituições que tendem a ser mais profissionalizadas dentro do universo das 338 mil organizações aferidas pelo IBGE no Brasil entre 2005 e 2008.

Na pesquisa, a Abong (2010) utilizou o paradigma qualitativo de análise aliando-o aos resultados de pesquisas quantitativas anteriores acerca das fontes de financiamento das associadas. Uma de suas principais conclusões é a de que os recursos do setor privado não são tão expressivos quanto em geral se supõe, não justificando que instituições substituam suas demais fontes de recursos, sobretudo as de cooperação internacionais, ainda que sob seu contexto de "queda", pelos financiamentos de mercado. Assim, entende-se que em vez de substituição de fontes de recursos em tempos de mudanças, um caminho que as associadas da Abong podem adotar é o da diversificação dessas fontes. Nessa mescla entre as fontes de financiamento das ONG, embora o montante dispensado pelas empresas privadas e suas fundações não seja tão impactante se comparado aos recursos das agências internacionais, entre as associadas à Abong, em 2007, 41,5\% acessavam esse tipo de recurso em alguma medida. (Abong, 2010, p. 14). Em tom semelhante, muito do que se entende por recursos provindos de empresas são, em verdade, recursos originários das fundações dessas empresas. Isso, em parte, pode ter um peso distinto das primeiras na tomada de decisão das ONG de bus- car ou não tal tipo de verba, já que muitas fundações empresariais possuem outro regimento, que não o da empresa necessariamente, o que confere a tais fundações certa autonomia relativa às propostas de projetos e parcerias com as entidades.

Ainda que de forma expressiva no que diz respeito à frequência com a qual aparece na pesquisa a presença de financiamento de empresas, essa relação de sustentabilidade ONG-Mercado não se sobressai quando considerados os percentuais de verbas vindos de cooperações internacionais, o que poderia parecer uma contradição haja vista o que tecemos sobre a redução de influência desse tipo de financiamento no Brasil. Porém, embora haja redução, este permanece como primeiro modelo de sustentabilidade financeira das associadas. A cooperação internacional chegou a constar em 78,3\% das entidades, estando em segundo lugar, antes das empresas privadas, o Estado, que só por parte do Governo Federal tem presença em mais de $60 \%$ das associadas, aparte das presenças dos governos estaduais e municipais que por suposto elevam esse percentual (Abong, 2010, p. 23).

A constatação maior dessa investigação sobre a sustentabilidade das associadas da Abong é a de que "a estrutura e a dinâmica de todos os fundos que sustentam uma dada organização têm pontos de interseção e interdependência muito fortes" (Abong, 2010, p. 39). Isso não significa que os fundos se unam necessariamente nos mesmos projetos internos às instituições, havendo uma construção de lógica interna na administração, utilização e acesso aos recursos recebidos. Evidencia-se uma estrutura complexa, uma rede na qual o próprio fato de ser ou não apoiada por determinada fonte já influencia no recebimento de outros recursos, ser financiado por $\mathrm{A}$ ou $\mathrm{B}$ pode ou não indicar credibilidade no cenário das ONG.

As associadas à Abong moldaram seus modelos de sustentabilidade apoiados nas agências de cooperação internacional. Criaram um padrão de captação de recursos que por vezes, ainda que necessário e reconhecido como tal, não é fácil de modificar, sobretudo porque a estratégia mais lógica das agências é planeada à base de justificativas, de uma "racionalidade justificável". Este modelo lógico de justificativa na busca por recursos parece já enraizado nas organizações de grande porte (Abong, 2010, p. 43) analisadas pela Abong que são, comumente, organizações que possuem mais complexidade de profissionalização institucional, haja vista a correlação expressiva entre ONG profissionalizada e ONG de grande porte (Melo, 2013). Como ponto de partida para o problema da sustentabilidade, está a capacitação da própria ONG em recorrer e se organizar de acordo

5. Apenas como um panorama de quem são as associadas à Abong, consideremos que, em 2008 , mais de $60 \%$ delas tinham um orçamento na faixa de até 1 milhão de reais brasileiros - BRL - anuais (cerca de 400 mil euros). Mais de 30\% tinham um orçamento anual entre 1 e 3 milhões de BRL e, da outra ponta, cerca de 2\% possuíam um orçamento anual de mais de 15 milhões de BRL (Gouveia; Daniliauskas, 2010). 
com as conjunturas, seja as alterações dos padrões de exigência das cooperações internacionais, seja as idas e vindas do barco político local. "As organizações de menor porte apontam recorrentemente a dificuldade em participar de seleção, via editais, dos fundos privados nacionais. Várias entrevistadas afirmam que a concorrência é grande, o processo de apresentação é complexo e demorado." (Abong, 2010, p. 43-44).

Da discussão sobre as organizações de maior ou menor porte e/ou com maior ou menor complexidade de profissionalização, não perdemos de vista que esses dados são uma projeção, um subsídio metodológico, pois são referentes às associadas à Abong e não representativos das ONG brasileiras, tampouco das ONG de um modo geral. Contudo, esboçam a carência de uma política efetiva e atualizada de sustentabilidade de organizações não governamentais, bem como, no caso brasileiro especificamente, de uma operacionalização prática e disponível das possibilidades de sustentabilidade, acessível a um conjunto maior de ONG e não apenas às de grande porte de que versa a pesquisa da Abong. Resposta a isso seriam os manuais, mencionados anteriormente, sobre como captar recursos ou quais as manobras possíveis para tal. Todavia eles se plantam em uma realidade normativa ainda precária, como fruto do modelo burocrático brasileiro e da mercantilização dos serviços relacionados ao Terceiro Setor (a venda do como proceder, do como operar).

É relevante considerarmos, por trás dessas discussões genéricas e polêmicas sobre a sustentabilidade, a necessidade das ONG terem sensibilidade para localizar quais as melhores formas de subsídios para o que perseguem. Ainda que visionária essa noção, quase à beira de um plano típico-ideal weberiano, ela busca uma percepção a evitar o que, a priori, é considerado por muitas delas como o desvirtuamento da missão, quando as $\mathrm{ONG}$ mudam suas missões para atenderem às demandas de editais e oportunidades de financiamento que encontram como oportunidade. Para isso, aqui em termos hipotéticos e desenhados com base nos exemplos numéricos aferidos em função das ONG da Abong, há uma necessidade de que essas ONG intuam a diversidade de opções de financiamento de acordo com os contextos em que se inserem.

\section{As lógicas da sustentabilidade em dois estudos de caso}

A sustentabilidade coloca-se como uma das principais dimensões analíticas no que se refere aos estu- dos sobre a profissionalização institucional. Por meio de dois estudos de caso brasileiros (Recife-PE), realizados ao longo de nossa investigação sobre a profissionalização institucional das ONG, buscamos estabelecer o fio condutor de questões, em prática, ocorridas nessas instituições no que diz respeito à sustentabilidade. O que nomeamos como ONG 01 é uma organização de pouca complexidade institucional e de gestão, de pequeno porte e que, também, apresenta um quadro de possibilidades limitado quanto à sustentabilidade. Já a ONG 02 é apresentada como uma entidade com complexidade de profissionalização institucional mais expressiva e que, embora também tenha limites na margem de manobra da sustentabilidade, possui um espectro mais largo e complexo de maneiras de sustentar-se, com base nos estoques de conhecimentos diversos. Optamos por caminhos metodológicos amparados na perspectiva qualitativa de análise. Realizamos estudos de caso com uma seleção de corpus composta por duas instituições em que foram realizadas observações diretas, observações participantes, análise documental e 37 entrevistas semiestruturadas. Em seguida, procedemos à análise dos dados por meio da análise de conteúdo, categorizando as informações com base em objetivos específicos de investigação previamente preparados. As duas ONG estudadas dedicam-se a meninas em situação de vulnerabilidade social.

\section{ONG 01}

Quando realizamos a primeira etapa da pesquisa de campo na ONG 01, em 2008, a entidade, além de realizar atividades com as adolescentes, contava com uma creche que atendia crianças de até quatro anos de idade. Essa creche era subsidiada pelo Conselho Municipal de Defesa e Promoção dos Direitos da Criança e do Adolescente (Comdica), vinculado à Prefeitura do Recife, mas fechou por falta de continuidade do subsídio. As crianças que lá estavam foram transferidas para outras organizações no bairro. O quadro pouco se alterou ao longo de nossa pesquisa longitudinal entre os anos de 2008 e 2013.

Os projetos voltados aos adolescentes são feitos para atendimento de seis meses a um ano, conforme solicita o Governo do Estado. “(...) temos um projeto feito por nós e eles dão a subvenção. A gente faz por seis meses, um ano e eles dão..." (Dona Lourdes, ${ }^{6}$ em 2012). Todavia, atualmente não existe nenhum em vigor, o que deixa a associação mantida basicamente por um projeto chamado "Todos com a nota", também

6. Todos os nomes aqui citados são fictícios.

7. Neste projeto, a ONG reúne notas fiscais e as trocam por subsídios. Este é um projeto governamental que busca fomentar uma cultura fiscal rigorosa contra à lógica de sonegação. 
do Governo do Estado. A quantia que conseguem arrecadar com a junção de notas fiscais não é suficiente para a manutenção dos gastos. Por isso, a entidade busca mecanismos paralelos de subsistência. Um deles é o de pedido de comida à Ceasa - grande mercado público de atacado alimentício - de alimentos que não seguem mais à venda. A mecânica é pautada pelo estímulo da presidenta da ONG e de sua família em doar tempo, e mesmo dinheiro, à instituição quando da oportunidade de receber alguma doação.

A lógica assistencialista permeia os discursos dentro da instituição quando tratamos da sustentabilidade. Atualmente, nem mais têm o auxílio de um projeto de ressocialização de presos, via Justiça Federal, tampouco projetos pela Secretaria de Educação da Prefeitura do Recife, como já o tiveram na época em que na ONG mantinham uma creche. Uma das principais razões que alegam os agentes para estarem sem financiamentos é que existe uma quantidade cada vez maior de entidades disputando recursos e, com isso, os órgãos financiadores recorrentemente preferem investir em outras associações. Percebem a importância das demais organizações, mas reclamam para si o direito de trabalharem com recursos suficientes às atividades propostas. "A gente tem tentado dentro dessas milhões de ONG que concorrem aos recursos. O problema é esse, que as outras recebem, recebem, recebem..." (Rita, elaboradora de projetos, em 2012). Ou então: "Deviam dar pra gente porque dar pras instituições que já têm tudo, que já têm muito... as grandes". (Dona Lourdes, em 2012). As saídas desses entraves é que são problemáticas na ONG 01, que não consegue desenvolver competências gerenciais para a manutenção das subvenções que possuem ou que já possuíram, assim como o que imaginam como meio de saída aos problemas financeiros ainda está num plano raso de ação, com ideias não estruturadas à captação de recursos: “(...) quando os projetos chegam ao fim a gente não tem sustentabilidade própria" (Rita, em 2012).

Ao planejamento administrativo, não existem projetos de captação de recursos capazes de manter a Sociedade nem por um prazo de um ano. A presidenta, nos picos de crise, costuma emprestar ou doar parte de sua reforma para não encerrar as atividades da associação. A instabilidade financeira, também responsável pelo "abrir e fechar" de portas de ONG, é uma das características mais marcantes na lógica administrativa da organização, uma vez que a entidade não recebe recursos provenientes do Segundo Setor, pois não está inserida em uma rede maior de comu- nicação com as demais ONG e não possui flexibilidade para galgar espaço de financiamentos de empresas privadas. O espectro de possibilidades de captação é restrito: “(...) eu já tentei procurar [recursos] pela net” (Rita, em 2012). Ao questionarmos por que não possuem outras fontes de financiamento, de empresas privadas, por exemplo, esboçam reticências como "aquilo já é jogo de cartas marcadas", todavia não pontuam as estratégias de captação que já tentaram seguir ou que seguem. Nesse amadorismo, falham nas estratégias de captação ao prenderem-se demasiadamente à lógica da doação que pode chegar (e não a de buscar). A organização é vulnerável a processos burocráticos e não assistida em seus direitos básicos, como o de ser isenta de impostos, no que paga taxas públicas por não conseguir articular na prefeitura a garantia de direitos.

Quando arguidos sobre as principais dificuldades da ONG, quase a unanimidade dos entrevistados referiu-se à sustentabilidade financeira da organização. Ao questionarmos os integrantes da instituição, em 2008, acerca da validade e da valorização ética/mo$\mathrm{ral}^{8}$ que faziam sobre receber recursos do Primeiro e Segundo Setores, não demonstraram nenhuma objeção, pois nunca se depararam com o dilema de receber determinado tipo de doação e nem se era ético e aceitável receber recursos provenientes do Mercado, alegando que não os tinham apenas porque as empresas nunca procuraram a organização para oferecer recursos e que apenas recusavam a inserção de políticos, candidatos a vereador, por exemplo, que quisessem penetrar na instituição para fins eleitoreiros. Mais uma vez, esse fenômeno ratifica que a entidade não possui flexibilidade e planejamento de submissão de projetos o suficiente para concorrer por financiamentos privados com as demais organizações. Todavia, quando da replicação das entrevistas em 2012, descobrimos que a organização já tinha recebido recursos via um deputado estadual, amigo de um dos filhos da presidenta. Esse fenômeno, tão negado no histórico da ONG em 2008, nos foi "confessado" em 2012, sobretudo, face ao "desespero" da eminência de fechamento da organização que hoje quase não possui financiamentos. Interessante notar que a lógica do que é "ético" altera-se de acordo com as conjunturas, no "a gente não queria, mas era o único meio de não ter fechada a organização naquele tempo", entretanto, só nos foi possível perceber essas saídas depois de longo contato na instituição. Mesmo assim, não foram todos os agentes que se dispuseram a falar sobre, gerando contradições compreensíveis nas falas

8. A ONG é fiscalizada periodicamente por representantes da Prefeitura e presenciamos algumas dessas visitas ao longo da observação participante. Notamos também a constante "prestação de contas" da presidenta a nossa pesquisa e a todos que circulam na ONG, bem como a valorização da transparência em todas as movimentações financeiras que executava, desde a compra de um remédio até a organização econômica como um todo. 
e explicadas pela própria conexão ética ao fenômeno. Verificamos não somente a intervenção desse político há alguns anos, como também a existência do projeto com os presidiários em ressocialização, porque os agentes não costumam divulgar a origem daqueles colaboradores, por serem pessoas que algum crime cometeram e estão em fase de cumprimento da pena. Sobre isso, alegam que os órgãos competentes eram responsáveis com os indivíduos que para lá enviavam, a exemplo de não permitirem que criminosos relacionados a crimes de pedofilia estivessem na entidade (que trabalha com crianças).

Veremos agora uma contraposição desse quadro com o exemplo dos processos da ONG 02 a fim de balizarmos as contribuições de diferentes caracterizações no entendimento da sustentabilidade de entidades no Brasil.

\section{ONG 02}

No que concerne a sua sustentabilidade financeira, uma das principais gestoras da instituição, em entrevista realizada em outubro de 2008 , aponta que é também uma das filosofias da entidade fazer que todos, desde a diretoria até os jovens atendidos, sejam captadores de recursos. A intenção maior dessa filosofia, de acordo com a diretoria, é promover uma descentralização do trabalho na tentativa de fazer que todos os participantes se envolvam com os problemas da ONG. ${ }^{9}$ Todavia, convém ressaltar que a moldura de divisão do trabalho da organização é especializada e setorializada, havendo uma equipe responsável pelos assuntos referentes à sustentabilidade financeira, bem como setores de administração e marketing, coordenadoria executiva, assessoria técnica, assessoria jurídica e setor de marketing e comunicação, isto é, um desenho administrativo que ratifica a existência de uma complexa profissionalização institucional.

A ONG se mantém com recursos provenientes do exterior, em sua maioria, ${ }^{10}$ seguindo essa lógica de financiamento desde a fundação, quando uma de suas fundadoras buscava dar visibilidade à problemática sobre a qual trabalhava no Brasil aos países europeus. Essas relações vêm se fortalecendo desde o fim da década de 1980, a expandir-se para diversos países além dos europeus, a exemplo de Canadá e Estados Unidos. Além de recursos provenientes do Mercado, a ONG também recebe verbas do Estado, dos governos federal, estadual e municipal. Os principais financiadores atualmente são: União Europeia, Petrobrás, Cáritas Alemã, Cedca, Cesvi, Christian AID/ComicRelief, Christian World Service, Criança Esperança (Unes- co, Rede Globo), Comdica, Consulado da Itália, Governo do Estado, Instituto Wallmart, Misereor, OAK Foundation, Prefeitura do Recife e TIM. Além dos financiadores, a ONG possui parceria com a Infraero, três centros comerciais do Recife, lojas, laboratórios, canal televisivo, empresas diversas e, também, com instituições de ensino superior como a Universidade Federal de Pernambuco (UFPE), Universidade de Pernambuco (UPE), Universidade Católica de Pernambuco (Unicap), Faculdade de Ciências Humanas de Olinda (FACHO) e Faculdade Maurício de Nassau, recebendo estudantes desses centros como estagiários e realizando pesquisas sobre as áreas de atuação da entidade, muitas das quais originaram livros e publicações sobre a instituição.

De acordo com a Diretoria de Marketing, a busca por financiamento também envolve a capacidade da ONG em sensibilizar seus financiadores sobre a importância de suas causas e a relevância de seus projetos. Segundo o responsável pelo setor, o crescimento do PIB brasileiro faz que alguns financiadores optem por investir em outros projetos, como os de países na África e na América Central, acreditando que os indicadores sociais do Brasil estão melhores, que a política do Governo Federal com programas como o Bolsa Família tem "resolvido" os problemas sociais, dentre outras leituras equivocadas que levam a conclusões de que tais investimentos sociais não se fazem mais necessários no País, desconsiderando o elevado índice de Gini de estratificação social, por exemplo.

De acordo com a diretoria, entretanto, de $70 \%$ a $80 \%$ do financiamento ainda provém do exterior, sobretudo, dos acordos com a União Europeia. A instituição tem cercado perenemente possibilidades com possíveis financiadores na Nova Zelândia e ou outros países. Curiosamente, encontramos nas entrevistas certa preocupação com relação a doações, todavia a palavra "doação" não surgiu nas falas com muita frequência ao longo das entrevistas que realizamos entre 2008 e 2013, diferentemente da ONG 01, e quando era citada vinha sob um complexo de possibilidades maior, a exemplo de que a doação de uma empresa internacional deveria ser aceita para que a ONG executasse seus projetos e retribuísse à sociedade e aos financiadores resultados estabelecidos pelas metas articuladas a priori. Palavras como "empoderar" ou "capacitar" são as que aparecem com grande frequência nas falas dos agentes da ONG 02, sob uma perspectiva de rompimento com as formas assistencialistas de sustentabilidade de uma organização. Por outra mão, estes significados incutidos na linguagem e na comunicação dos gestores são frutos

9. Tal tentativa de democratização não exclui a hierarquização e a especialização da divisão do trabalho na organização. 
de canais de comunicação comuns nos ambientes do Terceiro Setor, partilhados em uma filosofia conjunta por meio de redes, por exemplo, que traz à discussão temas como capacitação e empoderamento, que são naturalizados pelos agentes e permeiam o universo da ONG.

A política de transparência adotada pela instituição baseia-se no acompanhamento dos projetos pelos financiadores (accountability). ${ }^{11}$ Periodicamente, são enviados realisings aos colaboradores e relatórios das atividades, além da atualização do website da instituição com tais dados, pois, segundo os membros da diretoria, é necessário prestar contas não apenas aos financiadores, mas também à sociedade como um todo. Além disso, a prestação de contas e o fomento de transparência nas atividades desenvolvidas é uma ação estratégica de visibilidade, com a divulgação desse acompanhamento na imprensa. Para tal tarefa, existem agentes específicos, habituados a modelos de trabalho como este no Terceiro Setor.

O planejamento da instituição varia de acordo com os projetos financiados em vigor, tendo em consideração que eles possuem prazos diferentes, ou seja, um projeto pode acabar enquanto outro ainda tem garantia de financiamento por mais um ou dois anos. Em 2012, quando realizamos as entrevistas, o quadro mais geral era o de que alguns projetos encerravam-se naquele ano, mas o subsidiado pela União Europeia somente em 2014, todavia, a perspectiva era a de que quando o de 2014 encerrasse já deveria haver outros com prazos mais alongados e assim sucessivamente. Nota-se que esses projetos resultam em 90\% do financiamento da ONG. Percebe-se uma visão mais ampla ${ }^{12}$ de sustentabilidade, que não se reduz à sustentabilidade financeira e esta, por sua vez, não é sinônimo de apoio financeiro direto.

A respeito de possíveis restrições a determinados tipos de financiamento, o que havíamos investigado e analisado em 2008 permaneceu até 2012. Os entrevistados são pontuais ao dizerem que não recebem financiamentos de partidos políticos e/ou ordens religiosas. A única ocasião especial mencionada a respeito de restrições a financiamentos foi quando o Walmart lhes propôs parceria para subsidiar um projeto. Conta Reginaldo (2008-2012) que na altura os agentes se puseram a pensar se deveriam ou não receber aquele recurso, posto que a empresa tinha sido apontada nos EUA como exploradora das relações de gênero e a não respeitar direitos trabalhistas. Toda- via, findaram por aceitar a parceria ao "entenderem" que a proposta que o Walmart tinha para o Recife era diferenciada e que subsidiar ONG como aquela era uma atitude interessante do ponto de vista social. A preocupação que se coloca instrumentalmente ao caso é estratégica, voltada à conservação da imagem da entidade o que é, supostamente, uma preocupação com a manutenção de seu funcionamento em longo prazo. Prejudicar a imagem é, por consequência, prejudicar o trabalho. Ademais, os valores mercadológicos das entrevistas de um rapaz como o Vinícius, por exemplo, dedicado à comunicação e marketing da organização, são o guia de todo seu trabalho, o que não parece soar como um problema ideológico ter na instituição modelos de gestão semelhantes aos de Mercado. Inclusive, esses valores são apontados pelo entrevistado como o tronco administrativo mais pertinente para chegarem aos bens sociais que propõem à sociedade.

Em suma, a ONG 02 possui um quadro geral de financiamento interessante em comparação não apenas com a ONG 01, mas com a conjuntura geral das ONG no Recife. Articula-se em diferentes frentes e possui um planejamento estratégico solidificado às possibilidades emergentes das conjunturas política e econômica em que se insere. Entretanto, ainda que com agentes conscientes das possibilidades de financiamento que podem angariar como Terceiro Setor e, notadamente, por terem fontes majoritariamente provenientes do exterior, notamos nas falas da diretoria e das coordenações grande receio e insegurança diante dos novos quadros da imagem do Brasil no exterior como País em desenvolvimento que não precisa mais de incentivos, sobretudo após os últimos dados que colocam o País com o sétimo PIB mundial. Frisando que o Brasil tem uma alta taxa de estratificação social, essas percepções convertem-se em certo pessimismo com o futuro da ONG.

Recordamos que a ONG 02, diferentemente da ONG 01, é associada à Abong, o que a caracteriza em aspectos comuns com demais associadas que possuem maior inserção numa rede de informações apropriadas ao tema da sustentabilidade. Ainda assim, numa expressão diferente da ONG 01, a ONG 02 faz parte de um ecossistema frágil, vulnerável a ameaças externas conjunturais, como já ressaltara Salamon (1997). A falta de financiamento perene forma a grande marca do Terceiro Setor atualmente, seja numa configuração como a da ONG 01

11. Presenciamos algumas visitas da equipe do Instituto Walmart a um dos projetos ao longo da pesquisa de campo, nas quais os representantes dos financiadores realizavam reuniões com os professores, conversavam com as mulheres atendidas pelo Projeto, gravavam vídeos sobre as atividades etc.

12. Exemplo: ter um planejamento adequado ao funcionamento financeiro da organização não é, propriamente, uma consequência direta de sustentabilidade financeira, é anterior e passa a ser posterior quando retroalimentada por necessidades diversas. Outro exemplo de sustentabilidade não diretamente financeira é a capacidade de articulação em redes que tende a conferir possibilidades futuras de visibilidade da instituição. 
ou a da ONG 02. Nenhuma é capaz de gerir um plano extenso, a garantir o mínimo de estabilidade ao trabalho desenvolvido pelos agentes. Essa marca tão expressiva às ONG brasileiras é um dos fatores que mais repelem possibilidades de manutenção de agentes qualificados que, por questões particulares, findam por migrarem para outras possibilidades, sobretudo no Estado. As sazonalidades que ao Mercado competem, ainda assim, não encenam como mais expressivas do que as que dizem sobre o Terceiro Setor. A sustentabilidade põe-se aqui como o ponto frágil de toda a estrutura que, por mais profissionalizada que possa parecer, não escapa desses limitadores inerentes à dialética do Terceiro Setor. A lógica das ONG analisadas, especialmente a 02 , não se imuniza de uma proponente empresarial constante, tomando daquela elementos essenciais aos planos de gestão (Teixeira, 2003).

Como propunha Mintzberg (apud Aguiar; Martins, 2006), as dimensões que regem as entidades precisam ser minimamente integradas para que sobrevivam nesse modelo instável. A não integração, como posto ao caso 01, resulta nos problemas aqui relatados. Voltamos às principais premissas do autor com nosso campo em mãos: o que encontramos foi que uma estruturação eficaz de organização requer consistência entre os parâmetros de design e os fatores contingenciais que apontara Mintzberg. Os primeiros formam um sistema mais integrado em que as dimensões analíticas que propusemos ao estudo das entidades se colocam. Os aspectos são pontos interconectados e a alteração de um promove, em consequência, mudanças em todo o sistema de manutenção financeira da entidade. A harmonia das dimensões, baseada naqueles fatores contingenciais, atrelada à consciência de tais fatores face ao todo, é que possibilita um modelo menos instável de gestão financeira nas ONG. Esse exemplo foi verificado na ONG 02, quando da preocupação em tencionar imagem, fontes de financiamento, articulação entre diferentes projetos, preocupação com a lateralidade dos laços primários e secundários desenvolvidos dentro da organização (utilizá-los como estratégias aos demais aspectos citados), dentre outras categorias. Todavia, não percamos de vista que a proposta de Mintzberg é uma elaboração teórica, e mesmo na ONG 02 não existe uma integração completa entre as dimensões que a movimentam, havendo "bolhas de gás", muitas das quais reconhecidas pelos agentes que são profissionalizados às funções que exercem.
Se a integração fosse plena, muito possivelmente teríamos a análise de um "tipo perfeito" de entidade na ONG 02, o que não ocorre empiricamente.

Ainda que possamos dissertar sobre problemas administrativos e financeiros de ambas as organizações, na ONG 02, por exemplo, esses problemas já nos chegam nas entrevistas estratificados e identificados pelos próprios agentes, enquanto na ONG 01 perdemo-nos num universo demasiadamente amplo de problemas não localizados em suas particularidades, haja vista que "não ter financiamento" é uma consequência ampla dos pontos mais restritos de gestão. Todavia, a ratificar que sustentabilidade não é reduzida a sustentabilidade financeira, encontramos no exemplo da ONG 01 a preocupação com a falta de profissionais em falas que não faziam referência a financiamento. Eis quando o financeiro posiciona-se como o meio por qual passa a sobrevivência das ONG, mas que não se reduz a tais limitadores. ${ }^{13} \mathrm{Tal}$ aspecto ajuda-nos a não caracterizar entidades menos burocratizadas como fundamentalmente desprovidas de financiamentos, mesmo porque o "bem" pode ser materializado em serviços como o voluntariado e não, necessariamente, a um suposto valor monetário. Os aspectos centrais aqui analisados permaneceriam caso a ONG 01, por exemplo, ganhasse na loteria. $\mathrm{O}$ que a elevaria a posições materiais melhores das que dispõe hoje, não alteraria, consequentemente, sua complexidade profissional (a menos que aí recorressem a outros elementos formativos etc). $\mathrm{Ou}$ seja, a profissionalização institucional relaciona-se com o capital e com a sustentabilidade financeira, mas não é meramente correlacionada a esta, posto que as dimensões analíticas que dizem respeito a essa profissionalização são plurais. A sustentabilidade financeira, com suas contradições, encaixa-se como uma ponte para percebermos as motivações que ligam dimensões instrumentais e substantivas no cotidiano das organizações. É um eixo analítico no entendimento dos processos de profissionalização em que concluímos que o Terceiro Setor apresenta, através dessa sustentabilidade, um de seus mais frágeis aspectos. A profissionalização institucional das ONG tem papel importante na busca e manutenção dessa sustentabilidade, porém, os problemas de financiamento não são resolvidos de um todo com a complexificação da profissionalização institucional. Embora profissionalização e sustentabilidade sejam dimensões analíticas positivamente correlacionadas, não são estas categorias de análise reduzidas. 


\title{
Referências
}

AGUIAR, Andson; MARTINS, Gilberto. A teoria das estruturas organizacionais de Mintzberg e a gestão estratégica de custos: um estudo nas ONGs paulistas. Cont. Fin. USP, 2006. Edição Comemorativa.

ABONG. ONGs: repensando sua prática de gestão. Ed. Abong, 2007.

ABONG. Associação Brasileira de ONGs. Sustentabilidade das ONGs no Brasil: acesso a recursos privados. Realização Abong, Rio de Janeiro: Abong, 2010.

BAUMAN, Zigmunt. Modernidade e ambivalência. Rio de Janeiro: Jorge Zahar Editor, 1999.

CORCIONE, Domingos. Planejamento estratégico: algumas orientações. 1998.

DURKHEIM, Émile. Sociologia e filosofia. Rio de Janeiro; São Paulo: Forense, 1970.

DURKHEIM, Émile. Da divisão do trabalho social. São Paulo: Martins Fontes, 1995 [1893].

DURKHIEM, Émile. Da divisão do trabalho social. 2. ed. São Paulo: Martins Fontes, 1999.

GOUVEIA, Taciana; DANILIAUSKAS, Marcelo. Abong: panorama das associadas. São Paulo: Abong, 2010. IBGE. Gerência do Cadastro Central de Empresas. As fundações privadas e associações sem fins lucrativos no Brasil: 2005. Rio de Janeiro: IBGE, 2008. (Estudos e Pesquisas. Informação econômica).

LANDIM, Leilah. Múltiplas identidades das ONGs. In: HADDAD, Sérgio (Org.). ONGs e universidade: desafios para a cooperação na América Latina. São Paulo: Abong: Peirópolis, 2002a.
LANDIM, Leilah. É o momento de pensar na desconstrução do nome ONG. In: Revista do Terceiro Setor. 2002 b. LEBLON, Nathalie. The labor of loveand Bread: profissionalized and volunteer activism in the SP Women's Health Movement. 1998. Tese (Doutorado em Antropologia) Departamento de Antropologia, Universidade da Flórida, 1998.

LEITE, Antônio. Responsabilidade social empresarial ou investimento social privado? In: ABONG. Sustentabilidade das ONGs no Brasil: acesso a recursos privados. Rio de Janeiro: Abong, 2010.

MELO, Marina Féliz de. Profissionalização nas organizações não-governamentais. 2013. 345 f. Tese (Doutorado em Sociologia) - Universidade Federal de Pernambuco, Recife, 2013.

SALAMON, Lester. Estratégias para o fortalecimento do terceiro setor. In: IOSCHPE, Evelyn. $3^{\circ}$ Setor: desenvolvimento social sustentável. Rio de Janeiro: Paz e Terra, 1997.

SMith, Adam. A Riqueza das nações. Rio de Janeiro, Hemus, 1984 [1776].

TACHIZAWA, Takeshy. Organizações não-governamentais e terceiro setor: criação de ONGs e categorias de atuação. São Paulo: Atlas, 2002.

TEIXEIRA, Ana Claudia. Identidades em construção: as organizações não-governamentais no processo brasileiro de democratização. São Paulo: Annablume: Fapesp: Instituto Polis, 2003.

\section{Sustainabilities of NGO}

\begin{abstract}
This article discusses about NGO sustainabilities as an axis in understanding the professionalization processes in the Third Setor. Guiding the financial sustainability as an instrument which enables limits the existence of organizations, this research relies on qualitative paradigm of analysis and finds, as a result, a fragile third setor that depends on the sustainability, where the institutional professionalization of NGO has an important role in this scenario. Professionalization and sustainability are positively correlated, but the NGO professionalization does not guarantee the sustainability required.
\end{abstract}

Keywords: sustainabilities, financing, professionalization, NGO.

\section{Sostenibilidades de ONG}

\section{Resumen}

Este trabajo tiene como objetivo discutir las el carácter sostenible de las ONG como un eje analítico en el conocimiento de los procesos de profesionalización del Tercer Sector. Entendemos la sostenibilidad financiera como un instrumento que permite y, simultáneamente, limita la existencia de las organizaciones. La investigación se apoya en el paradigma cualitativo de análisis e encuentra, como 
resultado, un Tercer Sector frágil de acuerdo con la sostenibilidad, en el que la profesionalización institucional de las ONG desempeña un papel importante en este escenario. Aunque la profesionalización y la sostenibilidad sean dimensiones analíticas positivamente correlacionadas, la profesionalización de una organización no asegura la institución con respecto a su sostenibilidad financiera y a sus necesidades materiales que hacen posible el funcionamiento de la ONG.

Palabras clave: sostenibilidades, financiamiento, profesionalización, ONG.

Data de recebimento do artigo: 17/10/2016 Data de aprovação do artigo: 11/12/2016 